\title{
Long-term variability of storm surge frequency in the Venice Lagoon: an update thanks to 18th century sea level observations
}

\author{
F. Raicich \\ CNR, Istituto di Scienze Marine, Trieste, Italy \\ Correspondence to: F. Raicich (fabio.raicich@ ts.ismar.cnr.it)
}

Received: 24 November 2014 - Published in Nat. Hazards Earth Syst. Sci. Discuss.: 12 December 2014

Revised: - - Accepted: 18 February 2015 - Published: 11 March 2015

\begin{abstract}
Sea level observations made in the Venice Lagoon between 1751 and 1792 have been recovered, consisting of two time series of daily data on high and low waters in Venice and Chioggia. From comparisons with modern observations, the quality of the 18th century data appears to be good enough to allow a useful analysis. A composite time series of daily mean sea level is obtained by merging the 18th century data and 1872-2004 observations in Venice Punta della Salute. The absence of reliable information on vertical references prevents the connection of the two 18th century time series with each other and with modern observations. However, daily sea level anomalies relative to the mean sea level enable us to recognize storm surge events that appear to occur more frequently in the second half of the 18th century than in the late 19th and 20th centuries, particularly during the 1751-1769 period. The record-breaking storm surge of 4 November 1966 turns out to be a remarkable event even in comparison to the events extracted from the 18th century time series. Further work is required to fill the gap between the old and modern observations.
\end{abstract}

\section{Introduction}

The coastal communities in the north Adriatic region and particularly in the Venice Lagoon have always been sensitive to sea level variations, particularly the occurrence of storm surges and related floods, locally known as acqua alta (high water). Therefore, it is not a surprise that ancient chronicles on that subject date back to over 1000 years ago (Enzi and Camuffo, 1995).
Storm surges in the north Adriatic are the result of synoptic atmospheric forcing variability, and they are generally induced by southerly wind (sirocco) associated with cyclones over the western or central Mediterranean. The sea level rise connected with storm surges affects the whole Venice Lagoon almost uniformly. However, the interaction of the sirocco flow with the orography surrounding the northern Adriatic can result in a north-easterly wind flow (Bora) that produces an additional sea level increase in the lagoon, particularly at its south-western end (Camuffo, 1981).

Regular and still ongoing sea level monitoring in the north Adriatic started in the second half of the 19th century (for instance, tide gauges were installed in Trieste in 1859 and in Venice in 1871), and the time series provide long-term and accurate information about mean sea level (MSL) variability and storm surge frequency and intensity that has been exploited by several authors (see, e.g. Raicich, 2003, 2007, 2010; Pirazzoli et al., 2008; Lionello et al., 2012; Tsimplis, 2012; and references therein). However, earlier observations exist. The earliest quantitative observations of sea level height seem to have been made in Venice by Francesco Rinuccini in 1638 on Galileo Galilei's request by means of a pole (Rinuccini, 1966).

Sea level observations relative to local references were made between 1751 and 1792 in Venice, in the middle of the lagoon, and Chioggia, about $20 \mathrm{~km}$ from Venice at the southwestern end of the lagoon (Fig. 1). These data sources are particularly interesting because they provide regular observations on a daily basis made by educated persons with scientific backgrounds (medicine, natural sciences, physics, engineering). Therefore, although the observation methods and techniques do not comply with modern standards, they are 


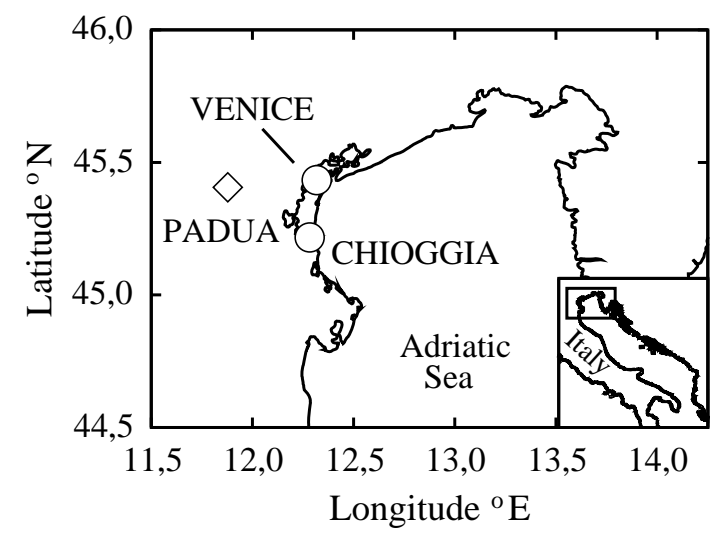

Figure 1. Map of the northern Adriatic region.

potentially useful for an analysis in conjunction with modern data. The availability of daily observations enables us to study the sea level variability on the synoptic time scale and in particular to investigate the occurrence of extreme events.

In principle, two viewpoints can be adopted to define the extreme events. One involves sea level anomalies relative to a suitable MSL (in time), which represent the effect of the atmospheric forcing, while the other makes use of sea level heights relative to a known vertical reference, accounting for the impact of the events on the coast. Unfortunately, the insufficient information about local references, in particular their stability, not only prevents adopting the second viewpoint but also does not allow us to connect the 18th century and the modern observations to a common vertical reference.

The main aim of this paper is to describe the analysis of a time series of daily sea level data useful to study the storm surge frequency in the Venice Lagoon since 1751. In the next section the data used in this work and their sources will be described together with the analytical methods. The methods used to derive the composite time series will be outlined in Sect. 3. Section 4 will include the analysis and discussion of storm surge frequency and interannual variability of monthly means of sea level. Concluding remarks will be presented in Sect. 5.

\section{The data}

\subsection{Eighteenth-century sea level}

Two time series of 18th century sea level observations were recovered, namely in Venice from 1751 to 1769 and in Chioggia from 1779 to 1782.

The Venice time series starts in 1751 thanks to the civil architect and hydraulic engineer Tommaso Temanza (17051789), who recorded meteorological and sea level data on a daily basis (Fig. 2, left). The observations cover the periods 1 January 1751-7 June 1757, 1 January 1765-30 June 1766 and 1 January-31 December 1769, with some mi- nor gaps, and they are available as manuscripts (Temanza, 1751-1769). The sea level observations consist of sea flux, sea reflux and the so-called water mass (massa dell'acqua in the original), corresponding to the difference between flux and reflux, and are expressed in Venetian feet and inches $(1 \mathrm{ft}=34.7735 \mathrm{~cm}, 12 \mathrm{in} .=1 \mathrm{ft}$; Martini, 1883). Although the Venice Lagoon is affected by a semidiurnal tide, Temanza does not report high and low waters but just one flux and one reflux per day, which very likely correspond to the daily highest and lowest sea levels respectively. This information is not explicitly stated by Temanza, but, on average, their difference is consistent with the total daily sea level range observed in modern data (this point will be discussed in Sect. 3). The text accompanying the observations explicitly reads "the water height is referred to the water comune, which is the fixed mark identified by the greenish mucilage left by salty water on stones". The water comune is also known as the comune marino (CM). The mucilage belt consists of algae and approximately corresponds to the mean high water; thus, the flux value is both above and below zero and the reflux value is almost always below zero. An open question is whether Temanza really refers his measurements to the algae belt or rather to a physical mark. In fact, a $C$ used to be engraved, sometimes above a short horizontal mark, at the upper edge of the algae belt on a wall or quay to indicate the $\mathrm{CM}$, which would be adopted as a reference for levelling. Temanza claims the mark to be stable (relative to the ground), which is true only if it is engraved; otherwise, its position follows MSL variability, adapting to new MSL conditions in approximately 2-3 months, depending on the wave motion (A. Sfriso, Ca' Foscari University, Venice, personal communication, 2014).

From 1779 to 1792 the physician Giuseppe Vianelli (1720-1803) made observations in Chioggia (Fig. 2, right). Two time series are available, partly overlapping. The main time series consists of heights and times of high and low waters from 1 January 1782 to 31 December 1792, published in the Ephemerides of Mannheim's Societas Meteorologica Palatina (Vianelli, 1784, 1785, 1786, 1787, 1788, 1789, 1790, 1793a, b, 1794, 1795). Two high and two low waters are generally observed every day because of the semidiurnal character of local tide. Another time series consists of 5-day mean high waters at syzygies and quadratures from 2 February 1779 to 29 December 1784, published in Chiminello (1789). During the 1782-1784 period, common to both time series, the 5-day means are verified to correspond to the averages of daily high waters; unfortunately, the daily values have not been found and therefore the information about storm surges cannot be extended back to 1779 . Sea level heights are measured by means of a vertical pole divided into Venetian feet and inches and represent the distance from the sea floor (Vianelli, 1784). Apparent times are provided, expressed as hora italica (Italian time), in which the day starts half an hour after local sunset (Vianelli, 1785). The time series is characterized by several individual missing days and short gaps of 

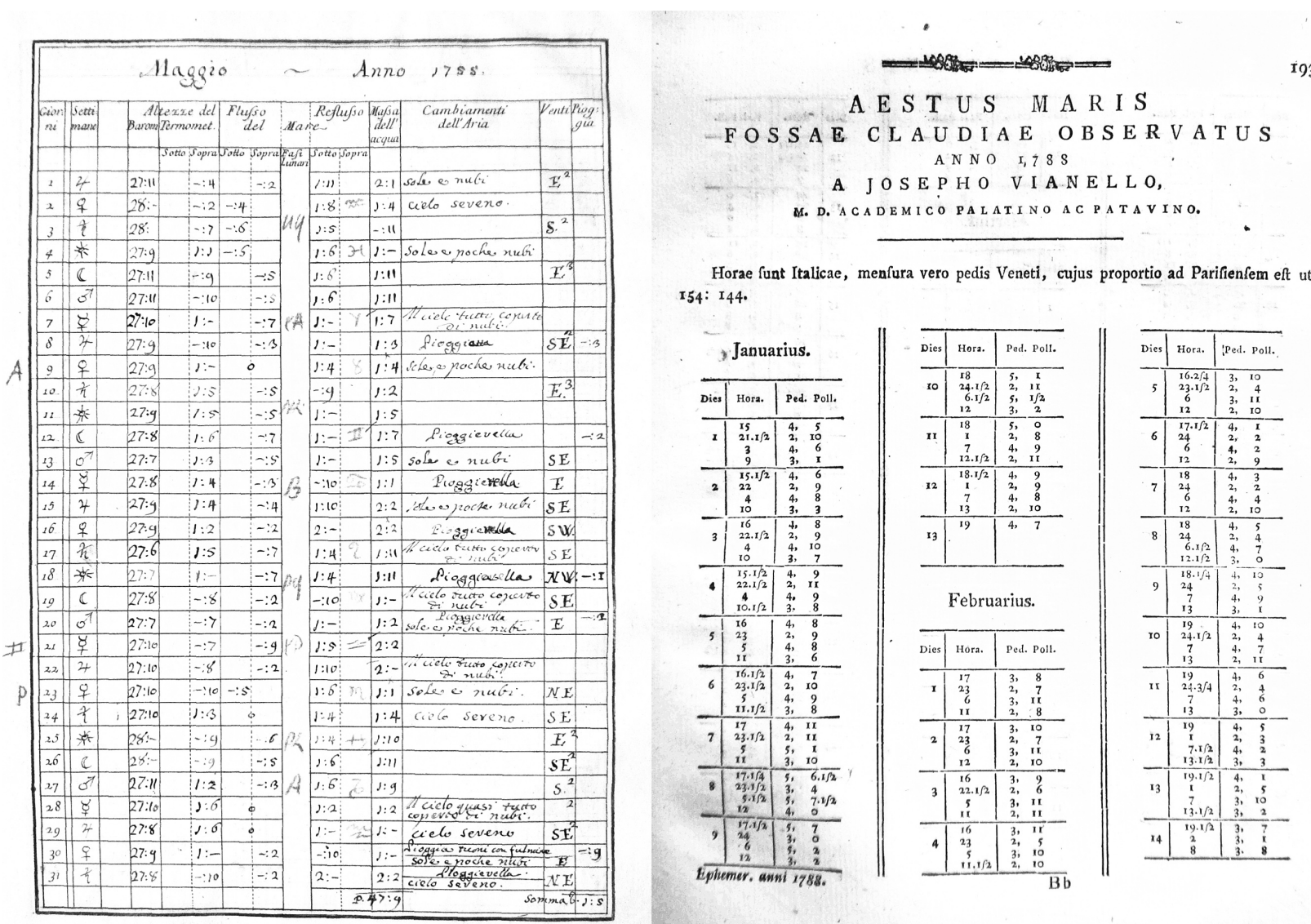

Figure 2. Temanza's manuscript for May 1755 (left; courtesy of the Historical Archive of INAF Astronomical Observatory, Padua). Chioggia data for January and February 1788 from Vianelli (1790) (right).

up to 10 days. Longer gaps, between 12 and 42 days, exist for unknown reasons other than due to the observer's absence in December 1787 (Vianelli, 1789), the lagoon freezing in January 1789 (Vianelli, 1793a) and a femur fracture suffered by Vianelli that caused several interruptions from February to August 1790 (Vianelli, 1793b).

\subsection{Other data}

Modern sea level data used in this work come from the 1872-2004 time series of high and low waters for Venice PS (Battistin and Canestrelli, 2006), and the hourly time series for Venice Punta della Salute (Venice PS) (1940-2012) and Chioggia Vigo (1989-2012) (obtained from the Venice office of the Italian Superior Institute for Environmental Research and Protection, www.venezia.isprambiente.it). To avoid confusion, in this paper Venice and Chioggia represent the 18th century sea level time series and Venice PS and Chioggia Vigo identify the modern time series. Cubic spline interpolation is used to estimate high and low waters in Chioggia Vigo. Correlations with the atmospheric pressure involve the 1725-1997 time series of daily values observed in Padua, lo- cated 35-40 km from both Venice and Chioggia (Fig. 1) (Camuffo et al., 2002).

\section{Daily sea level}

The accuracy of individual sea level measurements and times of observation is difficult to assess. From the original sources we can only deduce nominal precisions according to the least significant digits adopted, namely 1 in. (about $2.9 \mathrm{~cm}$ ) in Venice and $0.5 \mathrm{in}$. (about $1.5 \mathrm{~cm}$ ) in Chioggia. Time precision in Chioggia is $0.25 \mathrm{~h}$, while the times of the sea level extremes in Venice are not reported. We do not have details about the observation sites and conditions, if and how the effect of wind waves on each measurement is taken into account and if the observation is instantaneous or a sort of time average; a realistic error bar associated to an individual measurement in the most favourable conditions does not seem to be better than $\pm 3 \mathrm{~cm}$ (about \pm 1 in.). Times in Chioggia are converted to UTC+1 time before the data processing, taking into account the annual cycle of sunset time, which marks the day start. The $-11^{\prime}$ time lag, corresponding to the difference between local and $15^{\circ} \mathrm{E}$ longitude, is also included. 
The search for possible erroneous data and outliers is essentially based on the visual inspection of the time series and, in Chioggia, on the comparison between high and low waters and astronomical tidal predictions. As a result, 15 observations from Chioggia were considered suspect and rejected, while none from Venice were. The tidal analysis is made on the 1989-2012 data of Chioggia Vigo by means of the TASK-2000 software (Bell et al., 1999). Comparisons between observations and predictions are displayed in Fig. 3; note the occurrence of a remarkable storm surge which lasted a couple of days with a peak on 24 December 1792 (Fig. 3b). Clearly, tidal predictions derived from modern data represent the 18th century conditions only approximately, owing to the bathymetric and morphological changes that have occurred since then in the Venice Lagoon because of construction and excavation works (Rusconi, 1983; Camuffo and Sturaro, 2003).

A daily sea level mean is obtained by averaging the original observations for each calendar day. To compute a daily mean in Venice, both sea level extremes are required, while in Chioggia there must be an equal number of low and high waters (one or two). The daily sea level cycle is only approximately accounted for by high and low waters and not at all by the sea level extremes alone; therefore our daily means may significantly differ from the $24 \mathrm{~h}$ mean, which is often taken as a reliable standard. The bias can be estimated using modern Venice PS and Chioggia Vigo data. For each year and calendar day, the difference is computed between the daily mean obtained from data selected according to the same sampling schemes used in the 18th century and the daily mean obtained from $24 \mathrm{~h}$ data. These differences are averaged over the available years (1940-2012 in Venice PS and 1989-2012 in Chioggia Vigo), obtaining mean daily biases and related standard deviations that represent errors; a 30-day running mean is then applied to reduce the effect of the outliers. As a result, on average, the daily mean sea level in Venice computed from the extremes is always lower than the 24-hourly mean, with differences varying between $-4 \mathrm{~cm}$ in January and June and $-1 \mathrm{~cm}$ in October, with errors around $1 \mathrm{~cm}$ in all months. In Chioggia the average differences between daily means computed from high and low waters and 24-hourly values vary between $-0.2 \mathrm{~cm}$ in March to $0.4 \mathrm{~cm}$ in January, with errors between $0.2 \mathrm{~cm}$ in June and $0.6 \mathrm{~cm}$ in March. These errors are of the same size as the biases and appear to be quite tolerable for a study of storm surges.

A daily sea level anomaly is obtained as the difference between the observed daily mean and a MSL computed over a suitable time interval. This is represented by the lowfrequency sea level component of time scale longer than 6 months, as in Lionello et al. (2012), and is estimated by means of the objective analysis technique (Gandin, 1965; Bretherton, 1976). Thus, the sea level anomalies are little affected by the seasonal variability of sea level due to the steric effect, the ocean circulation and the semi-annual and an-
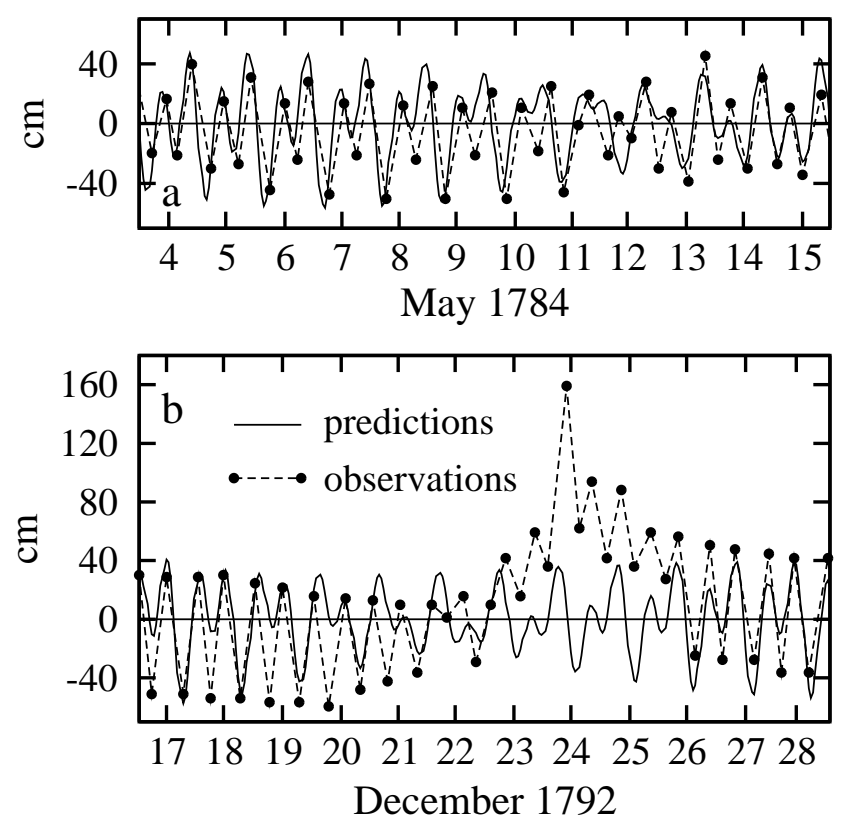

Figure 3. Comparison of observed data and tidal predictions in Chioggia from 4 to 15 May 1784 (a) and from 17 to 28 December 1792 (b). Ticks on the horizontal axes correspond to noon.

nual tidal constituents. Moreover, the influence of the abovementioned biases related to the daily sea level mean computation is also removed. For this reason, the daily biases are only taken into account during the computation of the monthly means (see Sect. 4.2).

The daily anomalies obtained from 1989-2004 high and low waters in Chioggia Vigo and Venice PS are highly correlated with $r=0.97$ ( $p \ll 0.01$ ); on average, Chioggia Vigo anomalies are approximately $1 \%$ larger than Venice PS anomalies. Using Venice PS 1872-2004 time series, the daily anomalies computed from sea level extremes are, on average, less than $1 \%$ smaller than those obtained from high and low waters. Thus, a composite time series of daily sea level anomalies can be produced by merging the 18th century sea level anomalies for Venice, with essentially no correction, with those for Chioggia, reduced by $1 \%$, and those for Venice PS obtained from high and low waters. We only take into account the data of the October-March period, when more than $90 \%$ of the notable storm surges are observed (Battistin and Canestrelli, 2006).

To check the consistency of the 18th century sea level anomalies, we also take advantage of the inverse barometer effect. Linear regression is used to quantify the inverse relationship between sea level and atmospheric pressure anomalies, obtained from the Padua 1725-1997 time series with the same filtering procedure used for sea level. The assumption is that a poor quality of either the sea level or the pressure data causes the anomalies to be uncorrelated and/or the inverse barometer coefficient unreasonable. In general, the inverse barometer coefficient obtained by linear regression of 


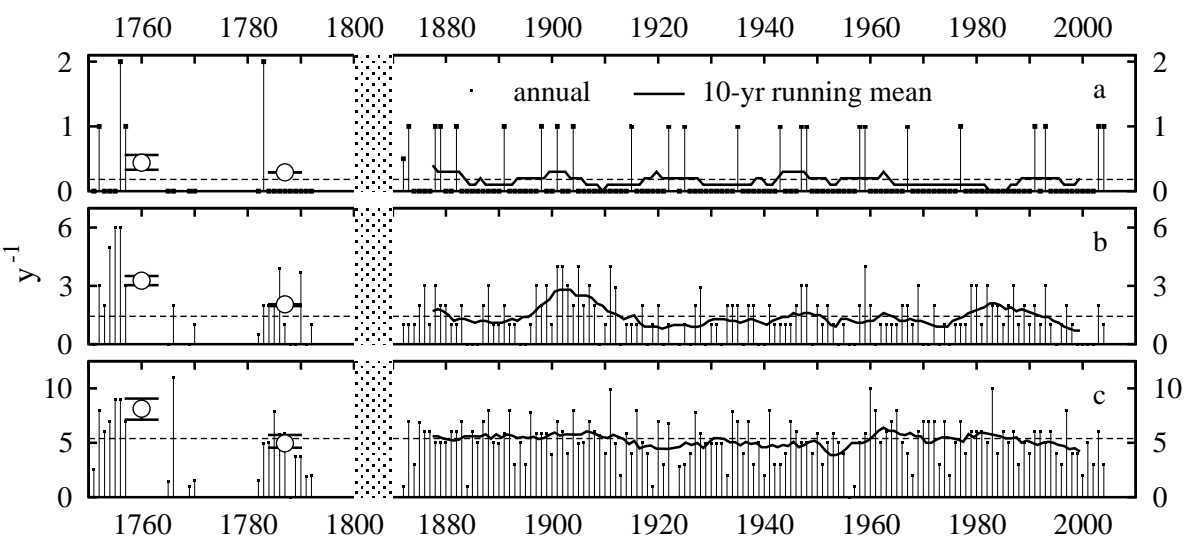

Figure 4. Frequencies of daily sea level anomalies above $55 \mathrm{~cm}(\mathbf{a}), 37 \mathrm{~cm}$ (b) and $25 \mathrm{~cm}$ (c), corresponding to the highest $0.1,1$ and $5 \%$ of daily anomalies in 1872-2004 respectively. Annual values are represented by vertical bars, pseudo-decadal means by white circles and 10-year running means by solid lines. Dotted horizontal lines represent the 1872-2004 means. The horizontal axis is interrupted for display purposes.

observations does not correspond to the theoretical value at equilibrium of approximately $-1 \mathrm{~cm} \mathrm{hPa}^{-1}$, obtained from depth-integrated equations of motion (e.g. Bowden, 1983), because the observed sea level variations, which are also connected to the local and remote wind field and modulated by local bathymetry, can often depart from ideal conditions. The inverse barometer coefficient also depends on the time scales of the low-frequency component used to obtain the anomalies.

The regression of Venice and Chioggia sea level and Padua pressure anomalies gives inverse barometer coefficients of -1.1 and $-0.9 \mathrm{~cm} \mathrm{hPa}^{-1}$ respectively; the linear correlation coefficients are $r=-0.6$ for both time series. For comparison, the regressions of Venice PS and Chioggia Vigo sea levels and Padua pressure, until 1997, are characterized by coefficients of -1.3 and $-1.2 \mathrm{~cm} \mathrm{hPa}^{-1}$ respectively and the linear correlation coefficients are $r=-0.7$ for both the time series. All linear correlations are significant at $p \ll 0.01$. The inverse barometer coefficients from old and modern data differ significantly (at $p<0.05$ ). This might be due to the different quality of the data and/or to the different response of sea level to atmospheric pressure variations, induced by the bathymetric changes occurred in the lagoon in the meantime. The analyses are limited to the October-March period, when the water column is less stratified than in spring-summer and the inverse barometer is generally more effective, but the results are identical if the whole year is taken into account.

It is possible to compare old and modern daily sea level ranges. In Venice the mean range between daily extremes increases from $(69 \pm 8) \mathrm{cm}$ in $1751-1769$ to $(77 \pm 5) \mathrm{cm}$ in $1872-1940$ and to $(81 \pm 5) \mathrm{cm}$ in $1941-2004$. Part of this change can probably be attributed to the works made since the late 19th century that modified the propagation of the tidal signal in the lagoon (Rusconi, 1983; Camuffo and Sturaro, 2003). The mean tidal range in Chioggia, corresponding to the difference between mean high water and mean low water, has remained essentially unchanged from $(54 \pm 8) \mathrm{cm}$ in $1782-1792$ to $(58 \pm 3) \mathrm{cm}$ in $1989-2012$.

\section{Results and discussion}

\subsection{Storm surges}

The storm surges of interest are represented by the daily sea level anomalies that exceed three selected height thresholds, corresponding to the highest $0.1,1$ and 5\% of the 1872-2004 Venice PS anomalies obtained from high and low waters, namely 55, 37 and $25 \mathrm{~cm}$, which select strong, moderate and weak surges respectively. For each calendar year we compute the number of events above each threshold observed from October of the previous year to March. Only complete October-March periods are taken into account; therefore remarkable events, such as the storm surge observed on 24 December 1792, may not be included in the statistics. From these data, average values are also obtained on a pseudo-decadal basis, namely from about 9 years of data in 1751-1769 and 1782-1792 and a 10-year running mean from 1873-1882 to 1995-2004 (Fig. 4). A sea level peak is sometimes followed by marked secondary peaks due to the fundamental seiche of the Adriatic Sea excited by the storm surge (Raicich, 1999). Therefore, to avoid the inclusion of such events that are not directly related to the meteorological forcing, only independent surges are considered, namely sea level anomaly peaks at least 3 days apart from each other

Means and standard deviations computed from the 1872 2004 decadal frequencies are $(0.2 \pm 0.1) \mathrm{yr}^{-1}$ for strong events (Fig. 4a), $(1.4 \pm 0.5) \mathrm{yr}^{-1}$ for moderate events (Fig. 4b) and $(5.4 \pm 0.5) \mathrm{yr}^{-1}$ for weak events (Fig. 4c). The 17511769 period is characterized by relatively high storm surge frequencies, particularly with regard to the strong and mod- 


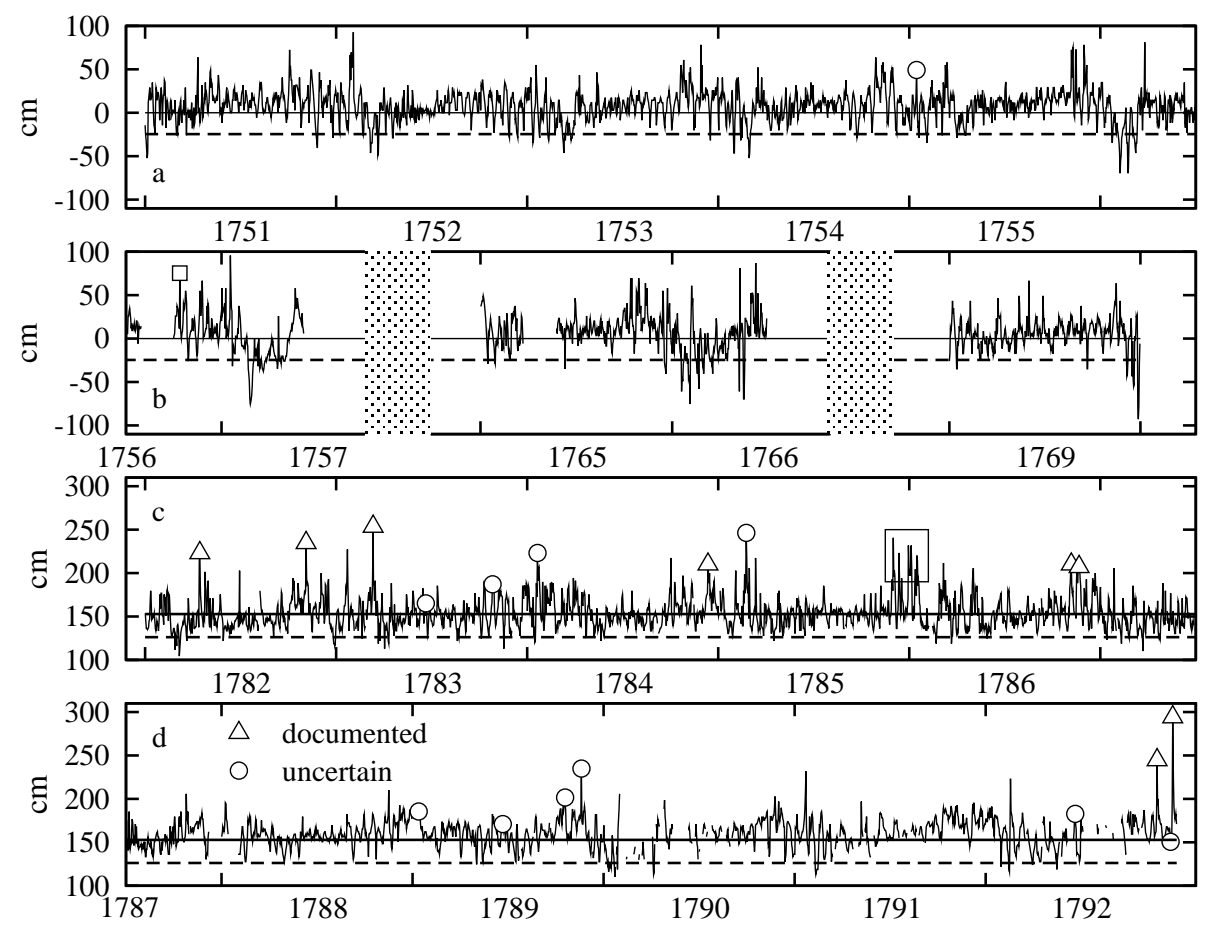

Figure 5. Daily sea level maxima for Venice (a, b) and Chioggia (c, d) in the original height scales converted to centimetres. Symbols indicate storm surge events quoted in Enzi and Camuffo (1995). The square in (b) indicates an event reported by Temanza (1751-1769) but not by Enzi and Camuffo (1995). The solid horizontal lines represent the CM in Venice (a, b) and the mean high water, as a proxy to the CM, in Chioggia (c, d). The dotted horizontal lines represent MSLs. The horizontal axis in (b) is interrupted for display purposes. See also text for more details.

erate events, with frequencies of 0.4 and $3.3 \mathrm{yr}^{-1}$ respectively (Fig. 4a and b). These values are approximately double the long-term averages but consistent with the highest decadal frequencies computed from the 19-20th century observations, which peak at $0.4 \mathrm{yr}^{-1}$ in $1873-1882$ and $0.3 \mathrm{yr}^{-1}$ in 1896-1905 for strong events and at $2.8 \mathrm{yr}^{-1}$ in 1898 1907 for moderate events. The 1751-1769 frequency of weak events is $8.1 \mathrm{yr}^{-1}$, i.e. $50 \%$ higher than the long-term mean and higher than any 19th-20th century decadal mean, whose maximum is $6.4 \mathrm{yr}^{-1}$ in 1958-1967 (Fig. 4c). In 1782-1792 the frequencies of strong, moderate and weak events are 0.3 , 2.1 and $4.9 \mathrm{yr}^{-1}$, which is somewhat lower than in 17511769 and more similar to the modern values (Fig. 4a-c). The uncertainty bars associated with the 18th century data represent frequency ranges under the hypothesis that individual 18th century measurements are affected by a $3 \mathrm{~cm}$ uncertainty (see Sect. 3). The annual number of events dealt with is small; nevertheless, it is interesting to note that the number of storm surges is larger in certain years in the 18th century than in any year from 1872 onwards. In particular, strong events occur twice a year in 1756 and 1783 and never more than once a year from 1872 onwards (Fig. 4a); the maximum annual number of moderate events since 1872 is 4 , while 5 events are observed in 1754 and 6 in 1755 and 1756 (Fig. 4b); the maximum number of weak events is 11 in 1766 compared to 10 in 1911, 1960 and 1983 (Fig. 4c).

As a result, the meteorological conditions favourable to strong storm surges appear to be more frequent in the second half of the 18th century than in the late 19th and 20th centuries. This is consistent with Camuffo and Sturaro (2004), who, based on documentary data (Enzi and Camuffo, 1995), find that the second half of the 18th century is a period with relatively high frequency of flooding surges. The comparison should be taken cautiously because the sea level data used in the present work cover just 18 years in that period. Note that if the sea level time series are filtered, removing the fluctuations of periods longer than 3 months instead of 6 , the daily anomalies are generally smaller in absolute value; nevertheless, the relative frequencies above the highest 5,1 and $0.1 \%$ thresholds do not differ significantly from those displayed in Fig. 4.

A cross-check is possible between the maximum daily sea levels reported by Temanza and Vianelli and the storm surge events listed in Enzi and Camuffo (1995) (Fig. 5). They report only one, uncertain, event in the 1751-1769 period, namely on 14 January 1755 (Fig. 5a, circle). From Temanza's observations this event does not seem remarkable and several tens of events appear to be more severe. By contrast, the Temanza manuscript reports a flood in Venice on 

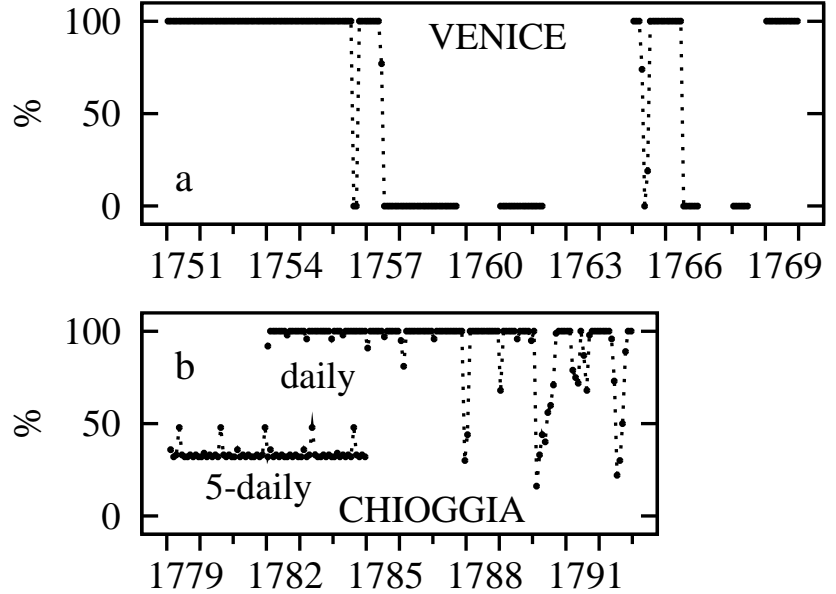

Figure 6. Monthly data availability in Venice (a) and Chioggia (b) as the percentage of days with data relative to the total. The absence of dots indicates that the data source is missing.

13 October 1756 when sea level attained $75 \mathrm{~cm}$ above the $\mathrm{CM}$, i.e. $100 \mathrm{~cm}$ above MSL (Fig. 5b, square); although it represents the eighth highest recorded event in the Venice time series, it is not listed in Enzi and Camuffo (1995). In the 1782-1792 period, Enzi and Camuffo (1995) list many more events: all the storm surges documented by direct witnesses correspond to sea level maxima at least $80 \mathrm{~cm}$ higher than the MSL (Fig. 5c and d, triangles), while uncertain events range from 20 to $120 \mathrm{~cm}$ above the MSL (Fig. $5 \mathrm{c}$ and d, circles). In December 1785-January 1786 multiple events are observed (see the box in Fig. 5c) while Enzi and Camuffo (1995) report a generic description of only one event in December 1785. A few strong events do not appear in Enzi and Camuffo (1995). A perfect correspondence between Enzi and Camuffo (1995) and the 18th century observations cannot be expected. However, the chronicles seem to report comparatively fewer events in 1751-1769 than in 1782-1792.

In the composite 1751-2004 time series the five highest daily sea level anomalies are observed on 4 November 1966 $(101 \mathrm{~cm}), 30$ November $1900(84 \mathrm{~cm}), 25$ February 1879 $(78 \mathrm{~cm}), 24$ December $1792(77 \mathrm{~cm})$ and 12 March 1783 $(71 \mathrm{~cm})$. The differing data reliability does not allow us to consider old and modern data strictly homogeneously; therefore the results must be taken cautiously. However, even allowing for the uncertainties in the 18th century daily anomalies the 4 November 1966 event represents a particularly outstanding event for centuries.

\subsection{Monthly means and trends}

Venice and Chioggia monthly MSLs are computed from the daily means corrected with the daily biases estimated as explained in Sect. 3. Following the criterion adopted by the PSMSL (2003), at least 15 days are required to compute a monthly mean. Figure 6 shows the data availability
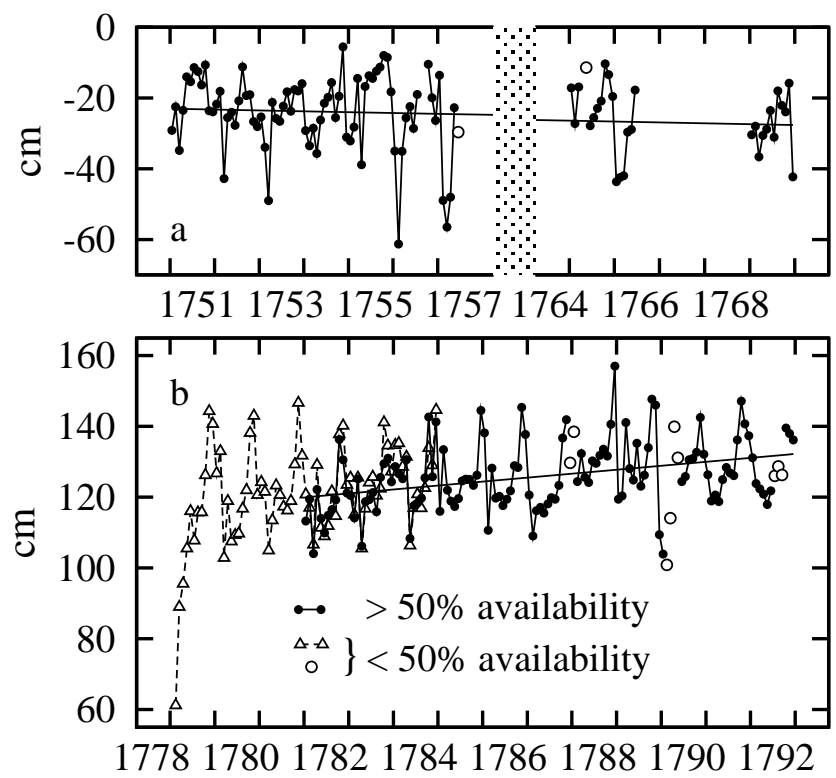

Figure 7. Corrected monthly means for Venice (a) and Chioggia (b). Straight lines represent linear fits. The horizontal axis in (a) is interrupted for display purposes.

on a monthly basis, represented by the percentage of days with observations. Venice monthly means can be obtained for January 1751-July 1756, October 1756-May 1757, January-March 1765, June 1765-June 1766 and JanuaryDecember 1769; for Chioggia they can be computed for January 1782-November 1787, February 1788-January 1790 , June 1790-June 1792 and September-December 1792. The time series of MSL, having applied the daily corrections discussed in Sect. 3.1, are displayed in Fig. 7; the MSL errors (not shown) are approximately $0.5 \mathrm{~cm}$ in Venice and about $0.3 \mathrm{~cm}$ in Chioggia, obtained by combining the bias error and a $3 \mathrm{~cm}$ error on each measurement (see Sect. 3). The 1751$1769 \mathrm{MSL}$ in Venice is $-25 \mathrm{~cm}$, and the $1782-1792 \mathrm{MSL}$ in Chioggia is $126 \mathrm{~cm}$; these values represent the sea level averages relative to the $\mathrm{CM}$ in Venice and the sea floor in Chioggia. The time series are too short to obtain robust linear trend estimates. In particular, the Venice time series (Fig. 7a) spans 18 years, but it only includes a continuous 6.5-year period (January 1751-May 1757) and two shorter periods separated by large gaps. Therefore, the physical significance of the estimated trend, namely $(-0.24 \pm 0.17) \mathrm{cm} \mathrm{yr}^{-1}$, is questionable. The linear trend estimated from Chioggia data is $(1.12 \pm 0.26) \mathrm{cm} \mathrm{yr}^{-1}$, which is much larger than the secular trend of $(0.24 \pm 0.01) \mathrm{cm} \mathrm{yr}^{-1}$ in Venice PS (Tsimplis, 2012) but consistent with recent decadal trends estimated from Chioggia Vigo data, namely $(1.06 \pm 0.23) \mathrm{cm} \mathrm{yr}^{-1}$ in $1989-2000$ and $(0.74 \pm 0.20) \mathrm{cm} \mathrm{yr}^{-1}$ in 2001-2012.

Unfortunately, the 1779-1784 Chioggia time series of 5-day mean high waters contains two (sometimes three) values per month, which is not enough to obtain reliable monthly means. Nevertheless, they show good consistency 
with the more reliable 1782-1792 time series (Fig. 7b). The low sea level in February 1779 may be partly due to data scarcity. However, that winter was characterized by persistent conditions of anomalously high atmospheric pressure with a February mean of $1031 \mathrm{hPa}$ in Padua (Camuffo et al., 2002).

\section{Conclusions}

Thanks to multidisciplinary scientists, sea level observations are available for the Venice Lagoon during part of the second half of the 18th century. They are certainly of lower quality than modern data and, moreover, little is known about vertical reference levels; nevertheless, the time series appear to be acceptable for an analysis. Clearly, the results should be interpreted with some tolerance.

Venice (1751-1769) and Chioggia (1782-1792) observations allow us to obtain (gappy) time series of daily sea level means as well as of monthly means. It is possible to build a composite time series of daily sea level anomalies relative to the MSL by merging the 18th century data and the observations made in Venice Punta della Salute since 1872, shortly after a regular tide gauge monitoring was started. Unfortunately, the absence of reliable information on vertical references prevents the construction of a unique homogeneous time series of relative sea level from 1751 to the present, and the short 18th century time series does not allow the estimation of robust linear trends.

The composite time series allows us to study the occurrence of storm surges and compare their frequencies in the second half of the 18th century and in the late 19th and 20th centuries. Storm surges appear to occur more often in the 1751-1769 period, while in the 1782-1792 period the frequencies of moderate and strong events are similar to those found in the late 19th century. Considering individual storm surges, the 4 November 1966 event appears to be the most severe one not only since 1872 but also in comparison with any event in the 18 th century time series.

Further data archaeology work is required to possibly recover missing information on vertical references as well as other sea level data, particularly to fill the gap between the 18 th century data and the modern observations.

Acknowledgements. The author thanks L. Pigatto and V. Zanini of the Historical Archive of INAF Astronomical Observatory, Padua, for giving access to T. Temanza's manuscripts containing the Venice sea level data. The author also thanks P. Woodworth and B. Martín-Miguez, whose comments helped improve the manuscript.

Edited by: D. Gomis

Reviewed by: P. L. Woodworth and B. Martin-Miguez

\section{References}

Battistin, D. and Canestrelli, P.: La Serie Storica delle Maree a Venezia, Istituzione Centro Previsioni e Segnalazioni Maree, Venice, Italy, 2006.

Bell, C., Vassie, J. M., and Woodworth, P. L.: POL/PSMSL Tidal Software Kit 2000 (TASK-2000), Permanent Service for Mean Sea Level, CCMS Proudman Oceanographic Laboratory, Bidston Observatory, Birkenhead, UK, 1999.

Bowden, K. F.: Physical Oceanography of Coastal Waters, Ellis Horwood, Chichester, UK, 1983.

Bretherton, F. P., Davis, R. E., and Fandry, C. B.: A technique for objective analysis and design of oceanographic experiments applied to MODE-73, Deep-Sea Res., 23, 559-582, 1976.

Camuffo, D.: Fluctuations in wind direction at Venice, related to the origin of air masses, Atmos. Environ., 15, 1543-1551, 1981.

Camuffo, D. and Jones, P. (Eds.): Improved Understanding of Past Climatic Variability from Early Daily European Instrumental Sources, Kluwer, Dordrecht, the Netherlands, 2002.

Camuffo, D. and Sturaro, G.: Sixty-cm submersion of Venice discovered thanks to Canaletto's paintings, Climatic Change, 58, 334-343, 2003.

Camuffo, D. and Sturaro, G.: Use of proxy-documentary and instrumental data to assess the risk factors leading to sea flooding in Venice, Global Planet. Change, 40, 93-103, 2004.

Chiminello, V.: Tavole della marea dei novilunj e plenilunj, osservata a Brest, e a Chioggia, Saggi scientifici e letterarj dell'Accademia di Padova, 2, 236-246, 1789.

Enzi, S. and Camuffo. D.: Documentary sources of the sea surges in Venice from AD 787 to 1867, Nat. Hazards, 12, 225-287, 1995.

Gandin, L. S.: Objective Analysis of Meteorological Fields, Israel Program for Scientific Translations, Jerusalem, Israel, 1965.

Lionello, P., Cavaleri, L., Nissen, K. M., Pino, C., Raicich, F., and Ulbrich, U.: Severe marine storms in the Northern Adriatic: characteristics and trends, Phys. Chem. Earth, 40-41, 93-105, 2012.

Martini, A.: Manuale di Metrologia, Ossia Misure, Pesi e Monete in Uso Attualmente e Anticamente Presso Tutti i Popoli, Loescher, Turin, Italy, available at: http://www.braidense.it/dire/ martini/indice.htm (last access: 14 August 2014), 1883.

Pirazzoli, P. A. and Tomasin, A.: Sea-level and surges in the Adriatic Sea area: recent trends and possible near-future scenarios, Atti Ist. Veneto Sc., Lett. Arti. Classe sc. fis., mat., nat., CLXVI, Venice, Italy, 61-83, 2008.

PSMSL: The Permanent Service for Mean Sea Level: Further Information, available at: http://www.psmsl.org/data/obtaining/psmsl. hel (last access: 14 August 2014), 2003.

Raicich, F.: Recent evolution of sea-level extremes at Trieste (Northern Adriatic), Cont. Shelf Res., 23, 225-235, 2003.

Raicich, F.: A study of early trieste sea level data (1875-1914), J. Coast Res., 23, 1067-1073, 2007.

Raicich, F.: On the contributions of atmospheric pressure and wind to daily sea level in the northern Adriatic Sea, Cont. Shelf Res., 30, 1575-1581, 2010.

Raicich, F., Orlić, M., Vilibić, I., and Malačič, V.: A case study of the Adriatic seiches (December 1997), Nuovo Cimento C, 22, 715-726, 1999.

Rinuccini, F.: Letter to Galileo Galilei, 15 May 1638, No. 3730, in: Le Opere di Galileo Galilei, nuova ristampa della Edizione Nazionale, vol. XVII, 262, Barbèra, Florence, Italy, 1966. 
Rusconi, A.: Il Comune Marino a Venezia, ricerche e ipotesi sulle sue variazioni altimetriche e sui fenomeni naturali che le determinano, Publication No. 159, Ufficio Idrografico del Magistrato alle Acque di Venezia, Venice, Italy, 1983.

Temanza, T.: Meteorological observations by various authors collected by Giuseppe Toaldo, Cod. XIII, Meteorological observations at Venice (Tom. I-II), unpublished manuscript, Historical Archive of INAF Astronomical Observatory, Padua, Italy, 17511769.

Tsimplis, M. N., Raicich, F., Fenoglio-Marc, L., Shaw, A. G. P., Marcos, M., Somot, S., and Bergamasco, A.: Recent developments in understanding sea level rise at the Adriatic coasts, Phys. Chem. Earth, 40-41, 59-71, 2012.

Vianelli, G.: Observationes aestus maris Autore Josepho Vianello, med. Doctore Clodiae in ora Veneta milliaribus 25 ad Austrum, Ephem. Soc. Meteor. Palat., 2, 251-260, 1784.

Vianelli, G.: Observationes aestus maris institutae Fossae Claudiae a D. Vianello, Ephem. Soc. Meteor. Palat., 3, 582-590, 1785.

Vianelli, G.: Aestus maris Fossae Claudiae, in ora Veneta, observatus an. 1784 a D. Josepho Vianello, Ephem. Soc. Meteor. Palat., 4, 234-242, 1786.
Vianelli, G.: Aestus maris Fossae Claudiae in littore veneto observatus a D. Josepho Vianello anno 1785, Ephem. Soc. Meteor. Palat., 5, 461-469, 1787.

Vianelli, G.: Aestus maris Fossae Claudiae in littore veneto, anno 1786, observatus a D. Josepho Vianello, Ephem. Soc. Meteor. Palat., 4, 321-336, 1788.

Vianelli, G.: Aestus maris observatus Fossae Claudiae in ora Maris Adriatici a D. Josepho Vianello, Ephem. Soc. Meteor. Palat., 7, 147-155, 1789.

Vianelli, G.: Aestus maris Fossae Claudiae observatus anno 1788 a Josepho Vianello, Ephem. Soc. Meteor. Palat., 8, 193-201, 1790.

Vianelli, G.: Aestus maris anno 1789 observatus Fossae Claudiae in ora Veneta, a Josepho Vianello, Ephem. Soc. Meteor. Palat., 9, 244-252, 1793a.

Vianelli, G.: Aestus maris Fossae Claudiae 1790, Ephem. Soc. Meteor. Palat., 10, 240-247, 1793b.

Vianelli, G.: Aestus maris observatus Fossae Claudiae ad oram Venetam Sinus Adriatici, a D. Josepho Vianello anno 1791, Ephem. Soc. Meteor. Palat., 11, 234-242, 1794.

Vianelli, G.: Aestus maris in Adriatico Sinu, ad oras Fossae Claudiae observatus a D. Josepho Vianello, M. D. anno 1792, Ephem. Soc. Meteor. Palat., 12, 234-216, 1795. 